\section{How important is immune memory to invertebrates?}

\author{
SIR - Margaret McFall-Ngai's Essay, \\ "Care for the community" (Nature 445,
}

$153 ; 2007)$ suggests that the unique existence of immune memory in vertebrates (the 'adaptive' immune system) could have evolved to recognize and manage beneficial microbe communities that invertebrates usually don't use.

This hypothesis is interesting and deserves consideration, although I would like to bring readers' attention to some earlier research, for example by J. Kurtz and K. Franz (Nature 425, 37-38; 2003), mostly by evolutionary ecologists, reporting immune memory in invertebrates.

The vertebrate immune memory is based on immunoglobulins that invertebrates lack. To date, we know almost nothing of immunememory mechanisms in invertebrates; hence the phenomenon has been observed before being mechanically understood. It is the opposite of the current trend in which genes are discovered before their functions are known, and is a good illustration of the importance of the complementarity of disciplines in biology.

Even so, the role and significance of immune memory in invertebrates remains unknown, and the interesting ideas discussed in this Essay could help to explain why this function might not be as central for invertebrates as it is for vertebrates. Simon Fellous

Laboratoire de Parasitologie Evolutive, CNRS-UMR 7103, Université Pierre \& Marie Curie, Paris 75005, France,

and Biology Division, Imperial College London, Silwood Park Campus, Ascot SL5 7PY, UK

\section{Getting that first scent of life while we're in the womb}

SIR - In the opening sentence of his excellent Brief Communication "Underwater 'sniffing' by semi-aquatic mammals" (Nature 444, 1024; 2006), Kenneth C. Catania states that mammals cannot smell underwater because it is impossible to inspire air. It is true that there is no air underwater; however, there has been a long debate about whether air is actually necessary to smell.

Ernst Heinrich Weber, a German physician who pioneered experimental psychology in the nineteenth century, heroically filled his nostrils with eau-de-Cologne diluted in water, and reported that he could not perceive the distinct smell of the dilution. Weber concluded that odours can only be smelled in air.

This was the reigning wisdom for the next 40 years, until Eduard Aronsohn repeated
Weber's experiment (Arch. Physiol. 321-357; 1886). Aronsohn reported a "horrible explosion of the most unpleasant and painful sensations in the nose" after filling it with diluted eau-de-Cologne. $\mathrm{He}$ learned from the experience, and from then on used a warm sodium chloride solution instead of cold water.

Aronsohn continued to do experiments on himself - and on colleagues and friends - with clove oil, camphor, eau-de-Cologne, coumarin and vanillin. He came to the conclusion that all odours could be smelled when he filled his nose with a dilution of each one in salt water.

Of course, this ability won't help humans to follow an earthworm scent trail in a river, as it does the ingenious star-nosed mole. But at least it allows us and other mammals to smell in the absence of air in the womb (B. Schaal, L. Marlier and R. Soussignan Chemical Senses 25, 729-737; 2000).

Andreas Keller

Laboratory of Neurogenetics and Behavior, Rockefeller University, 1230 York Avenue, Box 63, New York, New York 10021, USA

\section{Colour-blindness: how to alienate a grant reviewer}

SIR - With regard to recent Correspondence (Nature 445, $147 \& 364 ; 2006$ ) on the prevalence of scientific figures that are difficult for people with red-green colourblindness to read, I am compelled to support Chris Miall's position.

As a red-green colour-blind (deuteranope) scientist and graphic designer, I have long campaigned for figures to be accessible to an entire audience. I do so, in part, by leading seminars training my colleagues to create accessible figures.

One of the key resources I employ in this crusade is a website by Masataka Okabe and Kei Ito: http://jfly.iam.u-tokyo.ac.jp/html/ color_blind.

I strongly urge all authors to visit this site, which both describes the need for creating accessible images (including simulations of colour-blindness for those who are curious) and, more importantly, provides instructions for making figures comprehensible to everyone. This includes instructions on how to pseudo-colour images containing red and green fluorescent signals - one of the most hated types of graphic among people with colour-blindness. Authors will find it is surprisingly easy to accommodate the colour-blind when creating figures.

Anyone who needs to be convinced that making scientific images more accessible is a worthwhile task should consider that colourblindness is common, affecting $5-10 \%$ of males. If your next grant or manuscript submission contains colour figures, what if some of your reviewers are colour-blind? Will they be able to appreciate your figures? Considering the competition for funding and for publication, can you afford the possibility of frustrating your audience? The solution is at hand.

Joseph A. Ross

Peichel Laboratory,

Fred Hutchinson Cancer Research Center, 1100 Fairview Avenue North, Mailstop D4-100,

Seattle, Washington 98109, USA

\section{Sherlock Holmes's skills as a philosopher? Elementary}

SIR - Richard Gregory, in Books \& Arts, is not the only one to find professional inspiration in Arthur Conan Doyle's fictional hero Sherlock Holmes ("The great detective" Nature 445, 152; 2006).

See, for example, the work of Umberto Eco and Thomas A. Sebeok, comparing the reasoning methods of Holmes and of Edgar Allan Poe's detective, C. Auguste Dupin, with those of the logician Charles Peirce, in The Sign of Three: Dupin, Holmes, Peirce (Advances in Semiotics) (U. Eco and T. A. Sebeok, Indiana Univ. Press, 1984).

One might wish to follow Holmes's example with caution, however. As ably documented by Dr Watson in A Study in Scarlet, Holmes's scientific credentials are mixed. Watson's note, headed "Sherlock Holmes: his limits", includes:

\section{"[knowledge of] Astronomy: nil... Botany: variable. Well up in belladonna, opium, and poisons generally. Knows nothing of practical gardening. \\ Knowledge of geology: practical, but limited. Tells at a glance different soils from each other. After walks has shown me splashes upon his trousers, and told me by their colour and consistence in what part of London he had received them. \\ Knowledge of chemistry: profound... \\ Anatomy: accurate, but unsystematic."}

Famously, despite referring to his methods as "the science of deduction and analysis", Holmes was unable to distinguish between a deductive and an inductive inference. This failing might be accounted for by the fact that Watson also documented Holmes's knowledge of philosophy as "nil".

Philip Beaman

School of Psychology and Clinical Language Sciences, University of Reading, Earley Gate, Whiteknights, Reading RG6 6AL, UK

Contributions to Correspondence may be submitted to corres@nature.com. They should be no longer than $\mathbf{5 0 0}$ words, and ideally shorter. Published contributions are edited. 